\title{
Analysis of Foreign Video Streaming Service Entering Chinese Streaming Media Market: A Case Study of Netflix
}

\author{
Yiling Shi ${ }^{1, *}{ }^{*}{ }^{\dagger}$ Jialai $\mathrm{Zhou}^{2, \dagger}$ \\ ${ }^{1}$ AIEN Institute, Shanghai Ocean University (cooperated with the University of Tasmania), Shanghai, 201306, \\ Shanghai, China \\ ${ }^{2}$ School of Humanities, University of California, Irvine, 92697, Irvine, USA \\ *Corresponding author. Email: yilings@utas.edu.au \\ These authors contributed equally.
}

\begin{abstract}
Netflix, the leading video streaming service globally, has expanded to more than 190 nations in the last five years but hasn't been able to step into the Chinese market. However, being the largest population and booming Internet development, Netflix has flagged China as a potential market filled with potential and revenues. Therefore, this paper will make a study to explore how Netflix can occupy the Chinese video streaming market. To solve the research question, this paper utilizes the literature on the 4Ps theory and SWOT analysis, as well as make a comparison between the current situation of Netflix and Tencent Video, and the secondary data also be used to analyze the possibilities of Netflix's future development in China. The detailed SWOT analysis for Netflix concludes that the relatively high subscription price and strict censorship regulations will likely restrict Netflix's future expansion in China. At the same time, diverse and highquality products with good convenience have positive influences on its market development. To sum up, this article provides a reference for Netflix's future moves into the Chinese market and has significant implications for other streaming companies looking to enter the Chinese market.
\end{abstract}

Keywords: Netflix, Marketing Mix, China, SWOT, Streaming service.

\section{INTRODUCTION}

With the increasing speed of the Internet, nowadays, the popularity of electronic devices, and the significant impact of lockdowns due to global pandemic, video streaming services have been gradually taken over people's spare time in the last few years, billions of people are willing to pay a certain amount of money monthly for the access of a library of films, TV series, and reality TV shows. The rule of the traditional entertainment industry has broken, film and TV series started to release on streaming platforms rather than traditional movie theaters or television channels. As Netflix announced its memberships amount exceed 200 million internationals at the beginning of 2021, which $83 \%$ of its new subscribers in 2020 are residents outside of North America, it has undoubtedly become the leading company in the global video streaming industry [1]. Netflix was founded by Marc Randolph and Reed Hastings with online DVD rental services in 1997 and soon started its monthly subscription model after two years of operation. In 2007, it introduced online streaming services on Netflix.com, allowing members to watch videos online instantly. The well-known "Netflix Originals" projects were launched in 2013, making Netflix the pioneer in producing exclusive content among all subscription video on demand (SVOD) platforms [2]. Since its global expansion strategy starting in 2016, Netflix is currently available in over 190 counties, except China, Crimea, North Korea, or Syria [3]. Among these untouched nations, China is apparently the market with enormous potentials and revenues. According to "the 47th China Statistical Report on Internet Development", by December 2020, China has 989 million Internet users, of which $97.3 \%$ are using online video services, forming one of the largest markets of the streaming industry in the world [4]. The top three video streaming platforms in China are Tencent Video, iQIYI, and Youku. Although Netflix had a collaboration with the Chinese video platform, iQIYI, with a content licensing agreement involving popular series on Netflix, including "Black Mirror" and "Stranger Things," in 2017, it is still unable to officially access the Chinese market [5]. 
In recent years, there has been an increasing interest in Netflix's regions by region's localization strategy and how Netflix transferred young generations' viewing habits. In 2018, Dias and Navarro explained Netflix's competitive advantages and audience adaptations in the Brazilian over the top (OTT) market and future challenges in "Is Netflix Dominating Brazil" [6]. Researches by Ayten and others showed the idea of "binge racer" by Netflix and analyzed Generation Z and Generation Y's online viewing habits in 2019 [7]. Other researches include but not limit to Netflix's global branding strategy, Netflix's influences and relationship with the traditional Movie and TV industry, and how to apply Netflix's statistical data for better user satisfaction and recommendation system.

Abundant researches have been done about Netflix in marketing and business fields, and some include analysis between models of Netflix and online video platforms and the streaming market in China. However, most of them are mainly focused on iQIYI since it is dubbed as "the Netflix of China," has collaboration back in 2017, and has the biggest market shares in the past. As far as we know, no previous research has fully compared Netflix with other major Chinese SVOD platforms. According to Tencent's and iQIYI's First Quarter Financial Reports in 2021, Tencent Video, with 125 million paid users, surpassed the 105.3 million number of iQIYI, becoming the number one in subscription number among all SVOD platforms in China [8]. In this case, if Netflix decides to enter the Chinese market, Tencent Video will be its biggest competitor, so how does Netflix get a foothold in China in a decade? We, therefore, analyzed Netflix and the online video industry in China, investigated whether Netflix might be able to occupy the Chinese market in the next ten years and discuss possible challenges and pitfalls.

Based on Netflix's previous conspicuous strategies in localization in both content and marketing, our hypothetical conclusion is that Netflix is likely to succeed in the Chinese streaming market with its high-quality content and accurate recommendation systems with advanced data analysis applications. However, different viewing habits and high list prices might affect audiences' final subscription choices and be adapted locally depending on users' preferences. This paper will apply the Marketing Mix theory, especially 4Ps (product, price, promotion, and place) and 4Cs (consumer, cost, communication, and convenience), to review Netflix and its current global strategy. Next, we analyze Netflix using the SWOT model to compare with the top Chinese streaming platform, Tencent Video, to figure out its competitive advantages and disadvantages in the Chinese market, flowing up with discussion and suggestions.

\section{LITERATURE REVIEW}

\subsection{Marketing Mix}

Marketing mix generally refers to a company's comprehensive marketing plan, that is, the company's optimal combination and comprehensive use of various marketing factors under its control in response to the target market's needs. They can coordinate and cooperate with each other, avoiding the shortcomings of the strengths and advantages to achieve marketing objectives better. The marketing mix has been defined as the set of marketing tools the firm uses to pursue its marketing objectives in the target market, consisting of all factors that affect the demand for products. The term marketing mix was firstly coined in 1953 by Neil Borden in his inaugural address to the American Marketing Association [9]. The concept was adopted, and the twelve elements of the marketing mix were identified: product planning, Pricing, Branding, Channels of distribution, Personal selling, Advertising, Promotions, Packaging, Display, Servicing, physical, and physical handling, and Fact finding and analysis [9]. The original marketing mix includes Product, Price, Place, and Promotion (4Ps), proposed by marketer and academic E. Jerome McCarthy, providing a framework for marketing decision-making in 1960 [10]. McCarthy's marketing mix has since become one of the most enduring and widely accepted frameworks in marketing [10]. Thirty years later, Robert F. Lauterborn proposed a 4Cs classification. His classification is a more consumer-orientated version of the 4Ps, which attempts to fit the movement from mass marketing to niche marketing. The $4 \mathrm{C}$ (Customer, Cost, Convenience, and Communication) marketing theory is oriented to consumer needs and resets the four basic elements of the marketing mix: targeting the needs and expectations of consumers.

\subsection{Product}

A product is anything that can be offered to a market for attention, acquisition, use or consumption that might satisfy a want or need. It generally includes tangible goods and intangible services. The actual product is usually the parts, styling, features, brand name, design, packaging, quality level, and other attributes that combine to provide the core product benefits. In 2011, Dr. Ali and Fateme proposed that the product and price of the marketing mix influence consumer choice and play an important role in promoting customer loyalty in the cultural industry [11]. In 2015, Chandra et al. concluded through quantitative analysis and hypothesis testing that consumer desires can be satisfied by creating products with higher value [12]. 


\subsection{Price}

In a narrow sense, price is the amount of money charged for a product or service. Broadly speaking, price is the sum of all the values that customers give up to gain the benefits of having or using a product or service. It is the medium of exchange, taking many forms such as rates and tariffs, tolls, tuition fees, rent, interest, wages, and salaries. In Ruyi's research in 2016, she proposed that price can be used to reduce the competition from the foreign music industry: for the Korean music industry, lower price is the competitive strength competed with the American music industry [13]. Additionally, Sudari et al. proved the result by that both directly and indirectly price has the greatest impact on customer satisfaction and customer loyalty through customer satisfaction in 2019 [14]. In an article published by the International Journal of Contents in 2021, Kweon and Sang proposed that diversified pricing plans would improve the competitiveness of companies, attract more customers and increase customer loyalty [15].

\subsection{Promotion}

Companies must do more than just create customer value. They must use the promotion to communicate that value clearly and persuasively. The main promotional mix elements are advertising, public relations, personal selling, sales promotion, and direct marketing. The previously mentioned analytical experiments of Chandra et al. also demonstrate that differences in promotional variables affect consumer behavior [12]. The hypothesis testing and analysis conducted by Kom, Novela, and Scherly published in 2016 suggested that the most important factor influencing the decision to purchase wine is promotion [16]. Furthermore, in the article about customer satisfaction mentioned previously, apart from price, promotion, ranking second also positively affects customer satisfaction and loyalty of food and beverage products of SMEs in Malaysia [14].

\subsection{Place}

Placement involves delivering the value proposition of goods and services at the right place, in the right quantity, when the customer needs them. It is about where to sell products and the flow of goods and information throughout the supply chain, from the raw material stage to consumption and beyond. In "The Impact of Marketing Mix on Attracting Audiences to the Cinema", Mahmoud and Elham analyzed the results of 455 questionnaires by Kolmogorovian, binomial or relative, t-student, and Friedman tests to test for variables controlling for the 4P's [17]. They concluded place was the most influential variable in attracting viewers to offline film screenings [17]. The results of Abdelhady et al. study in 2019 using random sampling and multiple regression analysis showed a significant positive relationship between place, promotion, and product of marketing mix and passenger purchase decision [18].

\section{METHODOLOGY}

\subsection{Research Design}

This paper compares Netflix and Tencent Video in China. It analyzes the feasibility of Netflix's development prospect in China by means of qualitative research with SWOT analysis, along with the analysis and comparison of the current situation of Tencent Video. On the one hand, the reason for taking a qualitative approach for research is that there are few subjects to study, and there is no need to conduct a large amount of data analysis to quantify and calculate the problem and phenomenon, but only to examine whether Netflix has the attribute of being able to enter the Chinese market. Qualitative research supports adjustments to the method at any time during the research process and is relatively simple to organize, making it more flexible to research this way. In addition, Wong and Wickham used a qualitative research approach in their 2015 study on Marriott [19]. Kokas also used a qualitative research approach to study the impact of financialization [20]. On the other hand, for the reason why to make SWOT analysis, Wang Qian used a SWOT analysis in his article on Croatia's response to exploring the Chinese source market [21], and Jiaxing also used a SWOT analysis on the entry of Russian health food into the Chinese market [22].

\subsection{Data Collection}

This study will provide a comparative analysis of the 4Ps operated by Netflix and Tencent Video in the Chinese streaming market. The research objectives corresponding to Product, the 4Ps, are the current user base of both companies, the film, and TV production experience and works they already have, and the Chinese users' usage habits. Corresponding to the Price in 4Ps are the fees for movie purchases and membership purchases in the platform app. Place includes multiple platforms such as TV, computer, mobile, and others. Promotion corresponds to both successful and unsuccessful parts of the experience of promoting within the market. Most of this information comes from the literature survey. By reviewing and analyzing numerous literatures to extract the required data and information, secondary data, to conduct a feasibility analysis of Netflix's future entry into the Chinese market.

\subsection{Data Analysis}

\subsubsection{Strengths}

Since 2016, Netflix has generally expanded its services outside North America and has successfully 
become the major streaming platform in several nations by its superior and targeted "region by region" strategies. With its primary focus on localization, Netflix introduced mobile-only plans and drops prices to fit the preferences of potential users in various Asia-Pacific regions [23]. Producing original content in local languages is also key for Netflix's localization plan. Scared Games (2018), the first original series produced by Netflix for a breakthrough in India, gained a mass of new audiences and became the most popular Indian show on Netflix [24]. In this circumstance, its rich experiences and localization products while launching on a new market increase the likelihood of success in China. On the other hand, with its enormous library of diverse content, Netflix can also be attractive for the Chinese audience. According to Table 1, Netflix offers 5806 TV shows and films, of which $45 \%$ are non-English titles in 62 languages by 2020, proving a peerless pluralistic experience for users [25]. Compared to Table 2, by August 2021, Tencent Video is offering $6,247 \mathrm{TV}$ series, of which about $82 \%$ $(5,141)$ are made in Mandarin [26]. Another competitive advantage of Netflix is its advanced big data analytics for better understanding users and providing preferable products for individuals. It collects a vast amount of data from its millions of user base, including but not limited to locations, search history, and content watched, to offer a more personalized, accurate, and specific recommendation list and finally improve users' experience. While there is a recommendation section on Tencent Video's mobile app, it is not as precise and efficient as Netflix does and emphasizing more on promote the hottest and latest content instead of individual customization. Also, Netflix offers three subscription options (basic, standard, and premium) to fit users' different needs. Still, all include full access to its library, while in Tencent Video, extra pay is sometimes needed for specific films and TV series. Besides, Netflix is available on all devices, including TV, laptops, mobile phones once superscribed, perfectly convenient, and meet the daily demand for users in China.

Table 1. Number of Titles on Netflix by Language

\begin{tabular}{ll}
\hline Language & Number of Titles \\
\hline English & 3186 \\
Hindi & 552 \\
Spanish & 364 \\
Japanese & 214 \\
Mandarin & 203 \\
Korean & 147 \\
Arabic & 134 \\
French & 126 \\
Thai & 97 \\
Turkish & 84 \\
Portuguese & 61 \\
\hline
\end{tabular}

\begin{tabular}{lc}
\hline Cantonese & 59 \\
Tamil & 56 \\
Indonesian & 54 \\
Filipino & 49 \\
German & 47 \\
Malayalam & 43 \\
Punjabi & 30 \\
Italian & 28 \\
Polish & 26 \\
Malay & 24 \\
Other Languages & 230 \\
Adapted from What's on Netflix [25]
\end{tabular}

Table 2. Number of TV Series on Tencent Video by Region and Language

\begin{tabular}{lll}
\hline Region & Language Number of TV Series \\
\hline Mainland China & Mandarin 5010 \\
US & English $\quad 630$ \\
UK & English $\quad 167$ \\
Korea & Korean $\quad 134$ \\
Thailand & Thai & 74 \\
Japan & Japanese & 30 \\
Hong Kong (China) Cantonese 71 \\
Taiwan (China) & Mandarin 131 \\
& \\
Language & Number of TV Series \\
Mandarin & 5141 \\
English & 797 \\
Korean & 134 \\
Thai & 74 \\
Japanese & 30 \\
Cantonese & 71 \\
Adapted from Tencent Video $[26]$
\end{tabular}

\subsubsection{Weaknesses}

Price is a significant factor while choosing a monthly subscription. Argentina has the lowest price of Netflix at $\$ 3.28$ per month, which is 60 percent less than the basic plan price (\$8.99) in America. However, the monthly subscription price for Tencent Video after the latest adjustment in April increased to 20 Yuan (\$3), lowering than the $\$ 3.28$ of Netflix Argentina. This relatively higher price range is likely to limit potential customer groups and is unsuitable for the general public. Moreover, with only 203 titles of Mandarin content on Netflix, this deficiency of Chinese content is distinct and severe. In this case, producing and acquiring appropriate content is highly needed before entering China. Chinese audiences also have some disparate viewing habits than American habits. On Tencent Video, there is a comment and 
interaction section below each video for the audience to discuss thoughts, and bullet chats can be posted on the screen to share instant ideas. These interactive functions form an atmosphere of community and are considered indispensable for some Chinese audiences. At the same time, the lack of experience in producing and marketing can also become an obstacle while expanding into China.

\subsubsection{Opportunities}

Due to the invention of $5 \mathrm{G}$ technology and the booming Internet development, the international streaming service is progressing faster than ever in the last few years. The increasing number of people on the Internet brings tremendous opportunities and revenues for the streaming industry and Netflix in the next decade in China. Also, because of the global pandemic, people have to transfer their daily activity online as much as possible, making watching movies online not only a compromise but a preferable option and leading more audiences to online streaming platforms like Netflix. The Chinese government enhanced its copyright protection against pirated copies of film and television series in recent years. New regulations and movements are coming out every year to defend the legitimate rights of creators and streaming platforms.

\subsubsection{Threats}

The competitors of Netflix in China include local mainstream video streaming platforms, such as Tencent Video, iQiyi, and Youku. These domestic platforms own their unique original contents, have a large library of films, TV shows, and offer similar services to Netflix. Other entertainment substitutes, like music streaming app QQ music, social media platform Weibo, and short-video platform TikTok, compete with Netflix for audiences' spare time and attention. Since new entrants are constantly getting into the streaming industry, threats from new players also need to be noticed. However, the biggest threat for Netflix is definitely the strict and unavoidable film and television censorship policies that each film and television content published on the Chinese streaming website needed to be followed, including what can and cannot be included and how and when to release. In these circumstances, a large portion of content will be unavailable for Chinese audiences, and the releasing date has to be delayed due to the time for censorship in China.

\section{RESULT}

Netflix's product, including thousands of diverse contents, advanced data analysis applications, and rich localization experiences, is its biggest strength to attract new audiences in the Chinese market. In contrast, the lack of mandarin content can be fixed by producing and purchasing new shows and films. However, high prices and lack of experience in promotion might restrict Netflix's integrated development in China and need to be adapted locally. Although China is a market with unlimited opportunities due to the development of technology, the impact of the global pandemic and stricter copyright protection, threats from competitors (like Tencent Video), substitutes (like Tiktok), and new entrants gives uncertainties of Netflix's development in China. Most importantly, the film and television censorship model in China will seriously restrict the standard-compliant content released on Netflix and delay the releasing date in China.

\section{DISCUSSION}

The results of the research show that Netflix has limitations in entering the Chinese market. If Netflix's film and TV content are not in line with the relevant policies of the Chinese government, it may lose some original works and thus lose a very big Product advantage so that it is difficult to enter. Based on SWOT analysis and 4Ps theory, this research analyzes what advantages and disadvantages, opportunities, and challenges Netflix will have if it enters the Chinese market, and thus concludes that the most important thing Netflix needs to do if it enters the Chinese market is to maintain original productions and coordinate and balance with relevant Chinese policies. The result is consistent with Jiayi et al.'s view that Netflix needs to enter the Chinese market based on the national conditions, optimize policies, and create differentiated content resources, among other measures, as mentioned in the article Business Model Feedback System-based Business Model Analysis of Video Websites [27]. In the same year, Kim et al. published an article on the study of Chinese and Korean consumers paying for OTT services, mentioning the existence of the need for personalized recommendation services by platforms in the OTT market and the advantages Netflix possesses fit well with it [28]. This research adds that Netflix has personalized recommendations and its rich and diverse original works to develop. By taking advantage of these advantages, the threat of inconsistency between Chinese policy and Netflix content can be neutralized with greater probability. For the significance of this research, it is a useful reference for Netflix to enter the Chinese market in the future and other streaming media to enter the Chinese market. The limitation of this research is that the qualitative research is somewhat subjective, and the analysis results are not completely objective. In addition, the limitations of research objects, Netflix and Tencent Video, causing the existence of occasionality to some extent. From the perspective of future study, for other streamers, the research in this paper has some reference value, and they can further conduct quantitative research based on the current qualitative analysis.

\section{CONCLUSION}

This article presents a comprehensive SWOT analysis of Netflix in the Chinese video streaming market to 
obtain its advantages, disadvantages, and how it can expand into China in the next decade. This paper identified its diverse, advanced, and unique products as Netflix's biggest superior compared to its major competitor, Tencent Video. At the same time, the high progress of the Internet and change of people's viewing habits gives Netflix a favorable environment and opportunity in the future. On the other hand, higher prices, fierce competitions in the industry, and film and television censorship policy are likely to limit its further development to some extent. This paper continues to develop the application of the 4Ps theory and SWOT analysis on marketing, which is a guide to Netflix's next steps and trade-offs and a valuable reference for other streaming companies looking to enter the Chinese market in the short-term run. However, the study results are somewhat limited because the possibility of this question is currently analyzed only from the firm's perspective. A more comprehensive study on the feasibility of Netflix's entry into the Chinese market can be conducted in the future from the perspective of other different dimensions, such as the consumer perspective

\section{REFERENCES}

[1] Jarvey, Natalie. "Netflix Tops 200 Million Subscribers AMID PANDEMIC." The Hollywood Reporter, The Hollywood Reporter, 19 Jan. 2021, www.hollywoodreporter.com/business/digital/netfl ix-tops-200-million-subscribers-amid-pandemic$4118251 /$

[2] Petridis, S. "Netflix Original TV Series, or How Long-Form Films are Distributed as Serials." Academia Letters (2021): 2.

[3] "About Netflix - Netflix Is Now Available Around the World." About Netflix, 2021, about.netflix.com/en/news/netflix-is-nowavailable-around-the-world.

[4] “"The 47th China Statistical Report on Internet Development'-Office of the Central Cyberspace Affairs Commission." Cyberspace Administration of China of the People's Republic of China, 3 Feb. 2021, www.cac.gov.cn/202102/03/c_1613923423079314.htm.

[5] "About Netflix - IQIYI and Netflix Sign Licensing Agreement." About Netflix, 27 Apr. 2017, about.netflix.com/en/news/iqiyi-and-netflix-signlicensing-agreement.

[6] Dias, Murillo, and Rodrigo Navarro. "Is Netflix Dominating Brazil." International Journal of Business and Management Review 6.1 (2018): 1932.

[7] Ayten, A., and S. Bulat. "A Study of Generation Z Viewing Habits in Context of Uses and Gratification
Theory: The Protector Netflix Series Case." CTC 2019 (2019).

[8] GuDuo network, film and television. "love teng mans, B station, fast worker, who was the first to outperform the Q1 | interface news, entertainment." Interface news, 26 May 2021, www.jiemian.com/article/6145740.html.

[9] Borden, N.H. (1965), "The concept of the marketing mix", in Schwartz, G., Science in Marketing, John Wiley \& Sons, New York, NY, pp. 386-97.

[10] McCarthy, E.J. (1964), Basic Marketing, Richard D. Irwin, Homewood, IL.

[11] Dr. Ali Shahhosseini and Fateme Tohidy Ardahaey. "Marketing Mix Practices in the Cutural Industry." International Journal of Business and Management, Vol. 6, No. 8; August 2011.

[12] Chandra, Teddy, et al. "The Influence of Location, Products, Promotions, Services with Respect to Consumer Behavior." Review of European Studies, vol. 7, no. 12, 2015, pp. 48-58. EBSCOhost, searchebscohost-

com.ezproxy.utas.edu.au/login.aspx?direct=true\&d $\mathrm{b}=$ edshol\&AN=edshol.hein.journals.rveurost7.383 $\&$ site $=$ eds-live

[13] Zhao, Ruyi. Marketing Mix of the Music Industry in the United States and South Korea. EBSCOhost, search.ebscohost.com/login.aspx?direct=true \&db= edsrec\&AN=edsrec.2072.319179\&site=eds-live. Accessed 2 Aug. 2021.

[14] Sudari, S. A. (. 1. )., et al. "Measuring the Critical Effect of Marketing Mix on Customer Loyalty through Customer Satisfaction in Food and Beverage Products." Management Science Letters, vol. 9, no. 9, pp. 1385-1396. EBSCOhost, doi:10.5267/j.msl.2019.5.012. Accessed 28 July 2021.

[15] Kweon, Heaji J., and Sang Hee Kweon. "Pricing Strategy within the U.S. Streaming Services Market: A Focus on Netflix's Price Plans." International Journal of Contents, vol. 17, no. 2, June 2021, pp. 1-8. EBSCOhost, doi:10.5392/IJoC.2021.17.2.001.

[16] Kom, Novita S., et al. "Marketing Mix Analysis That Influence the Purchasing Decisions of Wine in DKI Jakarta and Tangerang." 2016 11th International Conference on Knowledge, Information and Creativity Support Systems (KICSS), Knowledge, Information and Creativity Support Systems (KICSS), 2016 11th International Conference On, Nov. 2016, pp. 1-5. EBSCOhost, doi:10.1109/KICSS.2016.7951430. 
[17] Mohammadian, Mahmoud, and Elham Sezavar Habibi. "The Impact of Marketing Mix on Attracting Audiences to the Cinema." International Business and Management, vol. 5, no. 1, Aug. 2012, p. 99. EBSCOhost, search-ebscohostcom.ezproxy.utas.edu.au/login.aspx?direct $=$ true \&d $\mathrm{b}=$ edsgao\&AN=edsgcl.304942853\&site=eds-live.

[18] Abdelhady, Mohamed R.Ragab, et al. "The Influence of Airlines' Marketing Mix Elements on Passengers' Purchasing Decision- Making: The Case of FSCs and LCCs." International Journal of Hospitality \& Tourism Systems, vol. 12, no. 2, July 2019, pp. 1-16. EBSCOhost, search-ebscohostcom.ezproxy.utas.edu.au/login.aspx?direct $=$ true $\& d$ $\mathrm{b}=$ hjh\&AN=136487504\&site $=$ eds-live.

[19] Wong, TL, and M. Wickham. An Examination of Marriott's Entry into the Chinese Hospitality Industry: A Brand Equity Perspective. Elsevier, 2015. EBSCOhost, search-ebscohostcom.ezproxy.utas.edu.au/login.aspx?direct $=$ true $\& d$ $\mathrm{b}=\mathrm{ir} 00480 \mathrm{a} \& \mathrm{AN}=\mathrm{UTAS} .20860$ \&site $=$ eds-live.

[20] Kokas, Aynne. "Chilling Netflix: Financialization, and the Influence of the Chinese Market on the American Entertainment Industry." Information, Communication \& Society, vol. 23, no. 3, Mar. 2020, pp. 407-419. EBSCOhost, doi:10.1080/1369118X.2018.1510534.

[21] Wang Qian. "SWOT Analysis and Related Countermeasures for Croatia to Explore the Chinese Tourist Source Market." Croatian International Relations Review, vol. 23, no. 78, Aug. 2017, pp. 169-185. EBSCOhost, doi:10.1515/cirr-2017-0012.

[22] Jiaxing Shang. "The Swot Analysis for Russian Health Product Entering the Chinese Market." International Multidisciplinary Scientific Conference on Social Sciences \& Arts SGEM, vol. 5, Jan. 2018, pp. 1155-1162. EBSCOhost, doi:10.5593/sgemsocial2018/1.5.

[23] Choudhury, Saheli Roy. "Netflix Bets Big on Asia as It Sees 'significant Potential' in These Markets." CNBC, 9 Nov. 2020, www.cnbc.com/2020/11/09/netflix-nflx-itsstrategy-in-asian-markets-like-india-indonesia.html.

[24] "Netflix and Its Battle for India." Fortune India, 24 Feb. 2021, www.fortuneindia.com/enterprise/netflix-and-itsbattle-for-india/105217.

[25] Moore, Kasey. "Does Netflix Have Too Much Foreign Content?" What's on Netflix, 6 Aug. 2020, www.whats-on-netflix.com/news/does-netflixhave-too-much-foreign-content.
[26] "TV Series - Tencent Video.” Tencent Video, 2021, v.qq.com/channel/tv?listpage $=1 \&$ channel=tv\&sort $=18 \&$ \&all $=1$.

[27] Jiayi, Rao, et al. "An Analysis on Business Model of Video Website Based on Business Model Feedback System-A Case Study of Netflix and iQIYI." Management Review 29.2 (2017): 245.

[28] Kim, Min Sung, et al. "Willingness to pay for overthe-top services in China and Korea." Telecommunications Policy 41.3 (2017): 197-207. 